\title{
ANALISIS PENGETAHUAN DAN PERILAKU PASIEN DM TIPE II DALAM PENGGUNAAN INSULIN SECARA MANDIRI DI INSTALASI RAWAT JALAN RSUD A.W SJAHRANIE SAMARINDA
}

\author{
Anjanie Medyawati Utami*, Welinda Dyah A, Victoria Yulita F, \\ Risna Agustina, Laode Rijai \\ Laboratorium Penelitian dan Pengembangan FARMAKA TROPIS Fakultas \\ Farmasi Universitas Mulawarman, Samarinda, Kalimantan Timur \\ *Email: anjaniemedyawatiutami@gmail.com
}

\begin{abstract}
ABSTRAK
Diabetes mellitus merupakan penyakit mematikan nomor 3 di dunia, dan Indonesia merupakan negara tertinggi ke 4 pengidap penyakit ini. Seiring dengan semakin bertambahnya penderita DM penggunaan insulin sebagai salah satu terapinya juga semakin meningkat, namun kesalahan terapi insulin cukup sering ditemukan dan menjadi masalah klinis yang penting. Bahkan terapi insulin termasuk dalam lima besar pengobatan beresiko tinggi (high-risk medication) bagi pasien di rumah sakit. Sehingga pengetahuan dan perilaku pasien harus mendapat perhatian lebih terhadap penggunaan terapi insulin agar optimalisasi terapi dapat tercapai. Tujuan dari penelitian ini adalah mengetahui karakteristik pasien DM tipe 2 yang menggunakan insulin, mengetahui tingkat pengetahuan dan tingkat perilaku pasien, serta mengetahui hubungan antara pengetahuan dan perilaku pasien dalam penggunaan insulin secara mandiri. Jenis penelitian ini bersifat prospektif. Teknik pengambilan sampel dengan cara purposive sampling. Populasi penelitian ini adalah pasien yang berobat di instalasi rawat jalan bagian poli penyakit dalam RSUD A.W Sjahranie Samarinda dengan banyak sampel 43 pasien. Hasil penelitian menunjukkan bahwa pasien DM tipe 2 di dominas oleh perempuan $51,16 \%$, pasien pada kelompok usia 46-55 39,53\%, pendidikan terakhir adalah SD 51,16\%, pekerjaan Ibu rumah tangga $41,86 \%$, serta pasien dengan riwayat keluarga yg mengidap DM sebanyak 76,74\%. Pengetahuan dan perilaku pasien dalam penggunaan insulin didominasi pada tingkat yang cukup baik yakni pengetahuan sebesar $72.09 \%$, dan perilaku sebesar $72,10 \%$. Hasil penelitian juga menunjukan adanya hubungan antara pengetahuan dan perilaku pasien yang signifikan, dimana semakin tinggi pengetahuan pasien maka perilaku pasien dalam menggunakan insulin akan semakin baik pula, hasil tersebut dibuktikan dengan didapatkannya nilai signifikansi (p) sebesar 0,000 .
\end{abstract}

Kata kunci: Diabetes mellitus tipe 2, insulin, pengetahuan, perilaku. 


\begin{abstract}
Diabetes mellitus is the third deadly disease in the world, and Indonesia is the 4th highest country of suffered that disease. Along with increasingly of Diabetes mellitus patients then using insulin as one of therapy is also increase, but the fault of insulin therapy is mostly found and becomes an important clinical problem. Insulin therapy is including of the top five high-risk medication for patients in the hospital. Cause that, the knowledge and behavior of patients should get more attention mainly about using insulin therapy so optimization therapy can be reached. The purpose of this research is knowing characteristics of DM type 2 patients using insulin, the level of knowledge and patient's behavior, and connection between knowledge and behavior of patients in using of insulin independently. This type of research is prospective. Sampling technique by purposive sampling. The population of this research were patients who's treated in installation outpatient of internal medicine polyclinic section in RSUD A.W Sjahranie Samarinda with many samples of 43 patients. The results showed that DM type 2 patients was dominated by $51.16 \%$ women, patients in the age group 4655 is $39.53 \%$, the last education is primary school is $51.16 \%$, housewife's job is $41.86 \%$, and patient who's had family history of DM is 76,74\%. Knowledge and behavior of patients in using insulin dominated at a fairly good level of knowledge is $72.09 \%$, and behavior is $72.10 \%$. The results also showing that connection between knowledge and behavior of patients was significant, which is increasingly of patient's knowledge then patient's behavior in using insulin also become mor better, the result was proved by the obtained value of significance ( $p$ ) of 0.000 .
\end{abstract}

Keywords: Diabetes mellitus type 2, insulin, knowledge, behavio

\title{
PENDAHULUAN
}

Diabetes Mellitus (DM) adalah penyakit kronis yang membutuhkan perawatan medis berkelanjutan sehingga dibutuhkan pengelolaan diri, pendidikan dan dukungan untuk mencegah komplikasi akut dan untuk mengurangi risiko komplikasi jangka panjang (ADA, 2012). Kepatuhan terapi pengobatan Diabetes Mellitus perlu ditekankan selama pengobatan, karena memiliki dampak yang besar terhadap pencapaian kontrol glikemik pasien Diabetes (Khardhori, 2013).

Adanya peningkatan penggunaan insulin ini, menyebabkan penderita diabetes mellitus yang menggunakan terapi insulin seharusnya perlu mengetahui dan mengerti bagaimana penggunaan insulin yang baik dan benar. Selain itu yang tidak kalah penting lagi penderita diabetes harus mematuhi hal tersebut agar tujuan utama terapi insulin dapat tercapai (Ejeta dkk, 2015). 
Kesalahan terapi insulin cukup sering ditemukan dan menjadi masalah klinis yang penting. Bahkan terapi insulin termasuk dalam lima besar pengobatan beresiko tinggi (high-risk medication) bagi pasien di rumah sakit. Sebagian besar kesalahan tersebut terkait dengan kondisi hiperglikemia dan sebagian lagi akibat hipoglikemia. Jenis kesalahan tersebut antara lain disebabkan keterbatasan dalam hal keterampilan (skill-based), cara atau protokol (rule-based) dan pengetahuan (knowledge) dalam hal penggunaan insulin (Perkeni, 2008). Ketidakpahaman dan perilaku buruk dari pasien sering disebabkan karena kurangnya pengetahuan dan pemahaman tentang obat dan segala sesuatu yang berhubungan dengan penggunaan obat untuk terapinya (Depkes, 2007)

Pada penelitian yang dilakukan oleh (Budiman, 2010) mengungkapkan terdapat 2 faktor pembentuk kepatuhan minum obat. Faktor kepatuhan yang pertama adalah karakteristik responden, terdiri dari umur, pendidikan, penghasilan, dan pengetahuan. Faktor yang kedua adalah perilaku. Dari proses pendidikan diharapkan akan terjadi perubahan pengetahuan, keterampilan, dan perubahan prilaku sehat dari pasien terhadap penggunaan obat-obat yang diberikan dalam terapi. Sehingga target terapi yang diharapkan dapat tercapai.

Menurut Roger (1997 dalam notoatmodjo 2007) mengatakan bahwa pengetahuan atau kognitif merupakan domain yang sangat penting dalam proses terbentuknya perilaku seseorang. Perilaku sehat sendiri adalah tindakan yang dilakukan individu untuk memelihara dan meningkatkan kesehatannya. Pengetahuan dan perilaku penderita DM merupakan sarana yang dapat membantu penderita menjalankan penanganan DM dengan tepat selama hidupnya. Sehingga semakin baik penderita mengerti tentang penyakitnya, maka pasien semakin mengerti bagaimana harus berperilaku dalam penanganan penyakitnya (Zimmerman, et al, 2008).

Hasil penelitian sebelumnya yang dilakukan di RSUD. AW. Sjahranie Samarinda tahun 2011 mencatat jumlah penderita DM tipe 2 tahun 2008 sebanyak 488 orang, diantaranya mengalami komplikasi 188 orang. Pada tahun 2009 berjumlah 497 orang, mengalami komplikasi 207 orang. Meningkat menjadi 582 pada tahun 2010 dan mengalami komplikasi 407 orang. Tahun 2011 berjumlah 
628 orang, mengalami komplikasi 484 orang, dan pada tahun 2012 dari bulan Januari - Juni berjumlah 803 orang, mengalami komplikasi 567 orang. Dari data tersebut menunjukkan bahwa terjadi peningkatan penderita DM tahun 2009 mengalami komplikasi 41,5\% dan tahun 2010 meningkat menjadi $70 \%$. Penyakit DM tipe 2 merupakan urutan ketiga dari jumlah kasus yang dirawat, selain itu DM tipe 2 merupakan urutan ketiga dari penyebab kematian (Gandini. 2015).

Berdasarkan hal tersebut maka perlu adanya penelitian mengenai analisis pengetahuan dan prilaku pasien DM tipe 2 terhadap penggunaan insulin, agar kurang optimalnya pengobatan akibat kurangnya pengetahuan yang berdampak terhadap kurang tepatnya perilaku pasien terhadap penggunaan insulin dapat diatasi dan keberhasilan pengobatan dapat tercapai. Penelitian dilakukan di Rumah Sakit Umum Daerah (RSUD) Abdul Wahab Sjahranie Samarinda

\section{METODE PENELITIAN}

Penelitian ini menggunakan desain cross sectional yang bersifat prospektif untuk mengetahui gambaran tingkat pengetahuan dan perilaku, dan hubungan antara pengetahuan dan perilaku penggunaan insulin pada pasien Diabetes Mellitus tipe 2. Penelitian ini menggunakan instrumen berupa kuesioner pengetahuan dan perilaku.

Populasi pada penelitian ini ialah pasien diabetes melitus tipe 2 yang menggunakan insulin, berusia 26-65 tahun, dan dapat berkomunikasi dengan baik. Teknik pengambilan sampel menggunakan teknik purposive sampling, dimana diperoleh 43 sampel pasien diabetes melitus tipe 2 yang menggunakan insulin di instalasi RSUD A.W Sjahranie Samarinda, pada periode Februari-Maret 2017.

\section{HASIL DAN PEMBAHASAN}

\section{Karakteristik Pasien}

Responden lebih didominasi terjadi pada kelompok perempuan yaitu sebesar 51,16\% dengan jumlah sebanyak 22 pasien. Hal ini dapat dilihat pada tabel 1. Wanita lebih berisiko mengidap diabetes karena secara fisik wanita memiliki 
peluang peningkatan indeks masa tubuh yang lebih besar. Sindroma siklus bulanan (premenstrual syndrome), pasca menopouse yang membuat distribusi lemak tubuh menjadi mudah terakumulasi akibat proses hormonal tersebut sehingga wanita berisiko menderita diabetes mellitus tipe2.

Tabel 1. Distribusi karakteristik pasien berdasarkan jenis kelamin.

\begin{tabular}{lcc}
\hline Jenis Kelamin & \multicolumn{2}{c}{ Jumlah } \\
\cline { 2 - 3 } & $\mathbf{N}$ & $\mathbf{\%}$ \\
\hline Perempuan & 22 & 51,16 \\
Laki-laki & 21 & 48,84 \\
\hline Total & $\mathbf{4 3}$ & $\mathbf{1 0 0}$ \\
\hline
\end{tabular}

Responden lebih didominasi terjadi pada kelompok usia 56-65 tahun (lansia akhir) $41,86 \%$ sebanyak 18 pasien. Hal ini dapat dilihat pada tabel 2. Menurut Garnita (2012), prevalensi diabetes mengalami kenaikan pada kelompok usia lansia tua diakibatkan karena proses penuaan menyebabkan berkurangnya kemampuan sel beta pankreas dalam memproduksi insulin.

Tabel 2. Distribusi karakteristik pasien berdasarkan usia

\begin{tabular}{lll}
\hline Usia & \multicolumn{2}{c}{ Jumlah } \\
\cline { 2 - 3 } & $\mathbf{n}$ & $\mathbf{\%}$ \\
\hline $16-25$ & - & - \\
$26-35$ & 1 & 2,33 \\
$36-45$ & 7 & 16.28 \\
$46-55$ & 17 & 39,53 \\
$56-65$ & 18 & 41,86 \\
\hline Total & $\mathbf{4 3}$ & $\mathbf{1 0 0}$ \\
\hline
\end{tabular}

Responden pada tabel 3, lebih didominasi terjadi pada kelompok tingkat pendidikan SD yaitu sebesar $51,16 \%$ dengan jumlah sebanyak 22 pasien. Pendidikan merupakan faktor penting dalam memahami penyakit, perawatan diri, pengelolaan penyakit, mengatasi gejala yang muncul dengan penanganan secara tepat serta mencegah terjadinya komplikasi. Sehingga kualitas hidup seseorang akan terjaga dengan optimal (Dwi, 2013). Penelitian yang dilakukan oleh Dwi (2013) 
menunjukan, seseorang yang memiliki tingkat pendidikan yang rendah (Sekolah Dasar) mempunyai risiko 1,9 kali lebih besar untuk memiliki kualitas hidup yang lebih rendah daripada yang berpendidikan tinggi sehingga resiko terkena diabetes mellitus tipe 2 semakin lebih besar.

Tabel 3. Distribusi karakteristik pasien berdasarkan tingkat pendidikan.

\begin{tabular}{lll}
\hline Pendidikan & \multicolumn{2}{c}{ Jumlah } \\
\cline { 2 - 3 } & $\mathbf{n}$ & $\mathbf{\%}$ \\
\hline Tidak sekolah/tidak lulus SD & 1 & 2,33 \\
SD & 22 & 51,16 \\
SLTP & 2 & 4,65 \\
SLTA & 7 & 16,28 \\
Sarjana/diploma & 11 & 25,58 \\
\hline Total & $\mathbf{4 3}$ & $\mathbf{1 0 0}$ \\
\hline
\end{tabular}

Responden pada tabel 4, lebih didominasi terjadi pada kelompok yang status pekerjaannya sebagai ibu rumah tangga (IRT) yaitu sebesar 41,89\% dengan jumlah sebanyak 18 pasien. Pekerjaan seseorang akan mempengaruhi tingkat aktivitas fisiknya, aktifitas fisik tersebut akan membantu mengontrol kadar glukosa darah. Pekerjaan seseorang mempengaruhi tingkat aktivitas fisiknya. Aktivitas fisik yang dilakukan oleh ibu rumah tangga kemungkinan besar lebih sedikit dibanding orang yang memiliki aktivitas pekerjaan diluar rumah. Orang yang aktivitas fisiknya ringan memiliki risiko 4,36 kali lebih besar untuk menderita diabetes mellitus tipe 2 dibandingkan dengan orang yang memiliki aktivitas yang sedang dan berat Sanjaya (2009).

Tabel 4. Distribusi karakteristik pasien berdasarkan pekerjaan.

\begin{tabular}{lll}
\hline \multirow{2}{*}{ Pekerjaan } & \multicolumn{2}{c}{ Jumlah } \\
\cline { 2 - 3 } & $\mathbf{n}$ & $\mathbf{\%}$ \\
\hline Pensiunan & 2 & 4,65 \\
PNS/TNI/POLRI & 11 & 25,58 \\
Wiraswasta & 7 & 16,28 \\
Pegawai Swasta & 2 & 4,65 \\
Ibu Rumah Tangga & 18 & 41,86 \\
Lain-lain & 3 & 6,97 \\
\hline Total & $\mathbf{4 3}$ & $\mathbf{1 0 0}$ \\
\hline
\end{tabular}


Responden pada tebal 5, lebih didominasi terjadi pada kelompok pasien dengan adanya riwayat dalam keluarga yaitu sebesar 76,74\% dengan jumlah sebanyak 33 pasien Timbulnya penyakit DM tipe 2 sangat dipengaruhi oleh faktor genetik. Bila terjadi mutasi gen menyebabkan kekacauan metabolisme yang berujung pada timbulnya DM tipe 2. Menurut Diabets UK (2010) risiko seorang anak mendapat DM tipe 2 adalah $15 \%$ bila salah satu orangtua memiliki DM. Jika kedua orang tua memiliki DM maka risiko untuk menderita DM adalah 75\%. Seseorang yang memiliki ibu dengan DM memiliki resiko 10-30\% lebih besar dari pada orang yang memiliki ayah dengan DM. Hal ini karena penurunan gen sewaktu dalam kandungan lebih besar dari ibu.

Tabel 5. Distribusi karakteristik pasien berdasarkan ada atau tidaknya riwayat keluarga yang menderita DM.

\begin{tabular}{lll}
\hline Riwayat & \multicolumn{2}{c}{ Jumlah } \\
\cline { 2 - 3 } keluarga & n & \% \\
\hline Ada & 33 & 76,74 \\
Tidak ada & 10 & 23,26 \\
Tidak tahu & - & - \\
\hline Total & $\mathbf{4 3}$ & $\mathbf{1 0 0}$ \\
\hline
\end{tabular}

\section{Analisis Pengetahuan Pasien dalam Penggunaan Insulin secara Mandiri}

Responden pada tabel 6, didominasi pada pasien dengan pengetahuan cukup yaitu sebesar 72,09\% dengan jumlah sebanyak 31 pasien.

Tabel 6. Distribusi pengetahuan pasien DM tipe 2 terhadap penggunaan insulin secara mandiri

\begin{tabular}{lll}
\hline Pengetahuan & Jumlah \\
\cline { 2 - 3 } & $\mathbf{n}$ & $\mathbf{\%}$ \\
\hline Baik & 7 & 16,28 \\
Cukup & 31 & 72,09 \\
Buruk & 5 & 11,63 \\
\hline Total & $\mathbf{4 3}$ & $\mathbf{1 0 0}$ \\
\hline
\end{tabular}


Mengenai tingkat pengetahuan ini, terdapat 10 daftar pertanyaan yang dijawab responden sehingga dapat disimpulkan kategori tingkat perilaku baik, cukup dan buruk

Pengetahuan pasien mengenai diabetes melitus merupakan sarana yang membantu pasien menjalankan penanganan diabetes selama hidupnya. Semakin banyak dan semakin baik pasien mengerti penyakitnya, maka semakin mengerti bagaimana harus merubah perilaku dan pola hidupnya, serta mengapa hal itu diperlukan. Pengetahuan merupakan faktor yang perlu diperhatikan dalam penatalaksanaan diabetes mellitus. Semakin tinggi pengetahuan pasien diharapkan akan meningkatkan pula kesadaran diri untuk melakukan kontrol glukosa secara mandiri dan penggunaan terapinya dengan tepat.(Notoatmodjo, 2013)

Dilihat dari karakteristik pasien yang didominasi oleh pasien yang berusia 5665 (Lansia Akhir), dan tingkat pendidikan SD. Dimana pada usia tersebut daya ingat seseorang telah menurun, dimana tingkat pendidikan juga memegang peran penting pada tingkat pengetahuan seseorang, sehingga hal tersebutlah yang mungkin mendasari belum baiknya tingkat pengetahuan pasien. Menurut Sugiharto dkk (2003), tingkat pendidikan dapat mempengaruhi kemampuan dan pengetahuan, semakin tinggi tingkat pendidikan maka semakin tinggi pula kemampuan seseorang dalam menjaga pola hidupnya agar tetap sehat. Hasil penelitian ini sesuai dengan penelitian yang dilakukan oleh Sartunus (2015), dimana pada penelitiannya didapatkan data bahwa pasien DM dengan tingkat pendidikan rendah mayoritas tingkat pengetahuannya cukup.

\section{Analisis Perilaku Pasien dalam Penggunaan Insulin secara Mandiri}

Responden pada tabel 7, didominasi pada pasien dengan perilaku cukup dalam penggunaan insulin secara mandiri yaitu sebesar $72,10 \%$ dengan jumlah sebanyak 31 pasien 
Tabel 7. Distribusi perilaku pasien DM tipe 2 terhadap penggunaan insulin secara mandiri.

\begin{tabular}{lll}
\hline Perilaku & Jumlah \\
\cline { 2 - 3 } & n & \% \\
\hline Baik & 8 & 18,60 \\
Cukup & 31 & 72,10 \\
Buruk & 4 & 9,30 \\
\hline Total & $\mathbf{4 3}$ & $\mathbf{1 0 0}$ \\
\hline
\end{tabular}

Mengenai tingkat perilaku ini, terdapat 12 daftar pertanyaan yang dijawab responden sehingga dapat disimpulkan kategori tingkat perilaku baik, cukup dan buruk

Perilaku seorang pasien menggambarkan seberapa patuh pasien tersebut dalam pengelolaan penyakitnya. Dimana menurut Siregar (2004) kepatuhan adalah tingkat ketepatan perilaku seorang individu dengan nasihat medis atau kesehatan dan menggambarkan penggunaan obat sesuai dengan petunjuk pada resep serta mencakup penggunaannnya pada waktu yang benar. Diabetes Mellitus merupakan penyakit kronis yang memerlukan adanya kesadaran pasien dalam berperilaku baik dalam penanganan penyakit secara mandiri seumur hidup. Selain harus memiliki perilaku preventif dalam gaya hidup untuk menghindari komplikasi diabetik jangka panjang, pasien juga harus memiliki keterampilan dalam menggunakan terapi yang harus digunakan setiap hari khususnya insulin guna menghindari penurunan atau kenaikan kadar glukosa darah yang mendadak, atau efek samping lain dari terapi yang digunakan.

Penelitian ini sesuai dengan penelitian yang dilakukan oleh Kristiantoro (2014), dimana responden didominasi oleh pasien yang dengan perilaku yang cukup sebesar 58,1\% dibandingkan dengan responden dengan perilaku baik sebesar $41,9 \%$ dalam penggunaan insulin secara mandiri.

\section{Analisis Hubungan Pengetahuan dengan Perilaku Pasien dalam Penggunaan Insulin secara Mandiri}


Tabel 1.8 Analisis Spearman-Rho pengetahuan dengan perilaku pasien dalam penggunaan insulin secara mandiri.

\section{Correlations}

\begin{tabular}{|c|c|c|c|c|}
\hline \multirow{7}{*}{ Spearman's rho } & & & pengetahuan & perilaku \\
\hline & \multirow[t]{3}{*}{ Pengetahuan } & $\begin{array}{l}\text { Correlation } \\
\text { Coefficient }\end{array}$ & 1,000 &, $866^{* *}$ \\
\hline & & Sig. (2-tailed) & . & ,000 \\
\hline & & $\mathrm{N}$ & 43 & 43 \\
\hline & \multirow[t]{3}{*}{ Perilaku } & $\begin{array}{l}\text { Correlation } \\
\text { Coefficient }\end{array}$ &, $866^{* *}$ & 1,000 \\
\hline & & Sig. (2-tailed) &, 000 & . \\
\hline & & $\mathrm{N}$ & 43 & 43 \\
\hline
\end{tabular}

**. Correlation is significant at the 0.01 level (2-tailed).

Perilaku penderita diabetes mellitus sangat dipengaruhi oleh pengetahuan, dalam hal ini pengetahuan penderita tentang penyakit diabetes mellitus sangatlah penting karena pengetahuan ini akan membawa penderita diabetes mellitus untuk menentukan sikap, berpikir dan berusaha untuk tidak terkena penyakit atau dapat mengurangi kondisi penyakitnya. Menurut Herlena (2013), Apabila pengetahuan penderita diabetes mellitus baik, maka perilaku terhadap terapi diabetes mellitus dapat mendukung terciptanya kepatuhan diabetes mellitus itu sendiri. Untuk mencegah terjadinya kesalahan dalam penggunaan insulin dan untuk meningkatkan tingkat kepatuhan maka pengetahuan sangat diperlukan oleh penderita diabetes mellitus, sedangkan pengetahuan itu sendiri merupakan dasar untuk melakukan suatu tindakan sehingga setiap orang yang akan melakukan suatu tindakan biasanya didahului dengan pengetahuan yang dimiliki, selanjutnya mempunyai inisiatif untuk melakukan suatu tindakan berdasarkan pengetahuannya, perilaku yang didasari oleh pengetahuan akan bersifat lebih baik dari pada perilaku yang tidak didasari oleh pengetahuan (Notoatmodjo, 2003).

Hasil dari penelitian menunjukan terdapat hubungan yang sangat signifikan antara pengetahuan dengan perilaku pasien terhadap penggunaan insulin secara mandiri di RSUD A.W Sjahranie Samarinda ( $p=0,000)$. Dimana semakin baik pengetahuan pasien terhadap penggunaan insulin maka perilakunya semakin baik 
pula, sehingga diharapkan kepatuhan pasien juga semakin baik, dimana akan berdampak pada semakin optimalnya pengobatan yang dilakukan.

\section{KESIMPULAN}

Hasil penelitian menunjukkan bahwa pasien DM tipe 2 di dominas oleh perempuan 51,16\%, pasien pada kelompok usia 46-55 39,53\%, pendidikan terakhir adalah SD 51,16\%, pekerjaan Ibu rumah tangga 41,86\%, serta pasien dengan riwayat keluarga yg mengidap DM sebanyak 76,74\%. Pengetahuan dan perilaku pasien dalam penggunaan insulin didominasi pada tingkat yang cukup baik yakni pengetahuan sebesar $72.09 \%$, dan perilaku sebesar 72,10\%. Hasil penelitian juga menunjukan adanya hubungan antara pengetahuan dan perilaku pasien yang signifikan, dimana semakin tinggi pengetahuan pasien maka perilaku pasien dalam menggunakan insulin akan semakin baik pula, hasil tersebut dibuktikan dengan didapatkannya nilai signifikansi (p) sebesar 0,000.

\section{DAFTAR PUSTAKA}

American Diabetes Association. 2012. Standards of Medical Care in Diabetes 2011. Diabetes Care. Vol. 34 (1): 511-561.

Departemen Kesehatan. 2009. Pedoman Teknis Penemuan dan Tatalaksana Penyakit Diabetes Melitus.

Ejeta, F., Raghavendra, Y., WoldeMariam, M., 2015, Patient Adherence to Insulin Therapy in Diabetes Type 1 and Type 2 in Chronic Ambulatory Clinic of Jimma University Specialized Hospital, Jimma, Ethiopia, International. Journal of Pharma Sciences and Research, Vol. 6 No. 4

Khardori, R., 2013, Type 2 Diabetes Mellitus Type And Managemen. Rineka Cipta: Jakarta

Notoadmojo, S. (2007). Pendidikan dan Perilaku Kesehatan. Rineka Cipta, Jakarta

Zimmerman, Gretchen, Cynthia G Olsen and Michael F Bosworth. 2008. A 'Stage of Change' approach to Helping Patien Change Behavior. Am Fam Physician. 6. (5).

Gandini, Andi Lis Arming. Dkk. 2015. Pendidikan Kesehatan terhadap Pengetahuan, Perilaku dan Gula Darah pada Pasien Diabetes Mellitus Tipe 2. Jurnal Penelitian. Vol. 3. No. 9.

Dwi, Wahyu. 2013. Analisis Kualitas Hidup Pasien Diabetes Melitus Tipe II di RSUD Bangil Kabupaten Pasuruan. Artikel Ilmiah. Vol 1. No.2

Sanjaya, I Nyoman. 2006. Pola Konsumsi Makanan Tradisional Bali sebagai Faktor Risiko Diabetes Melitus Tipe II di Tabanan. Tesi Universitas Sumatera Utara. 
Notoatmodjo, S (2013). Promosi Kesehatan Dan Ilmu Perilaku. Cetakan 2, Jakarta: Rineka Cipta.

Sartunus, Raphika. 2015. Hubungan Pengetahuan, Persepsi Dan Efektifitas Penggunaan Terapi Insulin Terhadap Kepatuhan Pasien Dm Tipe Ii Dalam Pemberian Injeksi Insulin. JOM. Vol 2. No 1

Herlena, 2013. Hubungan Antara Pengetahuan Dan Sikap Penderita Diabetes Mellitus Dengan Kepatuhan Diet Diabetes Mellitus Di RSUD Am. Parikesit Kalimantan Timur. Jurnal Keperawatan Medikal Bedah. Volume 1, No. 1 